\title{
Walking Threads: \\ A Memory and a Reflective Speculation Inspired by Gilles Deleuze and Félix Guattari
}

\author{
BRIAN SCHULTIS
}




\title{
Walking Threads: \\ A Memory and a Reflective Speculation Inspired by \\ Gilles Deleuze and Félix Guattari
}

\author{
BRIAN SCHULTIS
}

\begin{abstract}
A Memory of a 'Drifting' Walk
I remember the feel of the thread on my fingers, sometimes rough and biting, loose and fibrous at other times. I remember the feel of it on my shoulders and neck... fragile, out of scale with my body. I always wanted to keep it off the ground, and to do that I needed to keep alert to the tension that I could feel and to the ever changing pattern of gold that I could see, my concentration heightened from focusing on both sight and touch. I was more aware of my fellow walkers through this double awareness of the thread than by observing them directly, like a fisherman who perceives a fish through a line. Sometimes I was in the centre, other times I found myself at the periphery. Sometimes I was moving... making something happen. Other times I was a fixed point... keeping still while everything changed around me. It was a walk filled with lines, yet it was among the least linear walks I've ever taken. In fact it hardly felt like a walk, more like a float, or a drift. Yes, the water imagery feels right... as though all the thick swirling currents that work on your body when you walk or swim through water had been refined down into their most subtle form... compressed into the gentlest tug on a thread.
\end{abstract}

I also remember the people holding the thread... the many nodes on the web... my fellow drifters and the wind, sun, trees, and twigs joining us as we went along. There is a certain kind of intimacy that comes from floating together. I was not deciding what to do or where to go in response to others with whom I related as one independent subject to another, but implicated in the development of the pattern of thread which not only recorded all our movements but could be said to be the sum total of them. Intimacy is a surprising word for it, even though that is what it felt like, because it is not so much a question of being close to some 'other' but being lost in a greater totality in which the notion of other fades away. My being, in this instance, was expressed not by my individuality but by an evolving form which included people and things, which appear as others only upon retrospective reflection. I was not just in the drift of the thread through the park as an outsider who observed and sometimes affected it, but was that drift along with the four others. In my memory, separated by time, I think of this being the drift as a kind of intimacy with those four, and the whole environment.

\section{A Reflective Speculation}

Two points in this memory inspired by our walk in Seaton Park brought Gilles Deleuze and Félix Guattari to my mind. Namely the way I describe my position as constantly changing and my perception being the drift rather than being in it. In A Thousand Plateaus: Capitalism and Schizophrenia, Deleuze and Guttari make a distinction between movement and speed in relation to a body:

Movement designates the relative character of a body considered as 'one' and which goes from point to point; speed, on the contrary, constitutes the absolute character of a body whose irreducible parts (atoms) occupy or fill smooth space in the manner of a vortex, with the possibility of springing up at any point (1987: 381, emphasis in original).

This "possibility of springing up at any point" connects to my memory of constantly changing positions. Drifting is not simply undirected movement, but a changing of the character of body from something that moves from point to point to something that occupies or fills a smooth space. The thread played a crucial role in accomplishing this change of character by interrupting, for instance, my long distance vision. It led me to focus more on my physical sensations and the manipulation of the thread which appeared directly in front of me and which I could affect by my movement.

Inspired by art critic Aloïs Riegl, Deleuze and Guattari couple this kind of close vision with a particular kind of space. In their description, "the first aspect of the haptic, smooth space of close vision is that its orientations, landmarks, and linkages are in continuous variation; it operates step by step. Examples are 
the desert, steppe, ice, and sea, local spaces of pure connection" (1987: 493). Seaton Park is not ordinarily a space of this kind. Yet, through the attention demanded by the thread, it transformed.

The character of my body also transformed from being "considered as one" to a body whose irreducible parts stretched across the park. This quality, I think, led to my sense of being 'the drift'. My subjective self was superseded by a new individuation, a haecceity in Deleuze and Guattari's term, which they describe as "... a set of speeds and slownesses between unformed particles, a set of nonsubjective affects" (1987: 262). Deleuze and Guattari never describe this kind individuation as intimate. Intimacy, for them, comes on another plane, where there are not only nonsubjective affects but also subjects capable of feeling. Later though, when the drift had ended, I think that intimacy was the way my body remembered having been a haecceity, in this particular case the haecceity of a drift of thread and bodies on a cold sunny afternoon. Perhaps intimacy is nothing else.

Deleuze and Guattari see individuation as a haecceity, as something to be achieved: "You have the individuality of a day, a season, a year, a life (regardless of its duration) - a climate, a wind, a fog, a swarm, a pack (regardless of its regularity). Or at least you can have it, you can reach it" (1987: 262). If so, Walking Threads is an experiment in finding a method for reaching an individuation as a haecceity. This is a paradoxical idea in that any kind of method or attempt guided by the will presupposes individuation as a subject who undertakes the attempt. Yet the experience of walking threads demonstrates how we might live with this paradox. Walking with thread is not an action with predetermined results but a practice which can engage people and landscape in a way that makes it likely that a haecceity may appear. Further connections, between our 'Walking Threads' walk and that of Deleuze and Guttari have been taken up and expanded upon by Peter Loovers and Paola Esposito in different ways (this issue). Personally, though, it is this tentative association between smooth space, speed, haecceities, and intimacy that excites me about what happened that afternoon - when walking with a length of thread opened up new connections and possibilities for intimacy between people and with places. I'm still following where this thread leads.

\section{References}

Deleuze, G. \& F. Guattari (1987). A Thousand Plateaus: Capitalism and Schizophrenia. Minneapolis: University of Minnesota Press. 